\title{
SIMPLIFIED DIGITAL CONTROLLER FOR VARIABLE FREQUENCY INVERTER FED THREE-PHASE INDUCTION MOTOR
}

\author{
G. A. Abo Ahmed**, S. A. Kalilah* and A. E. Mobarka* \\ *Electrical Engineering Department, Faculty of Engineering, \\ Minoufiya University, Shebin-EL-Kom, Egypt, \\ ** Damonhour power station, Beheira, Egypt.
}

\begin{abstract}
This paper presents a simplified approach for a digital controller of variable frequency three-phase inverter supplied a three-phase induction motor. The performance characteristics with variable frequency supply have been studied and simulated by a computer program. The torque-speed characteristics of the motor varied with variation of the frequency. Torque-speed characteristics at different frequencies are presented. Interesting waveforms of the digital controller have been recorded. Frequency variation covers many industrial applications such as manufacturing rollman belly, water pumps, composers, chiller fans and some home application.
\end{abstract}

في هذا البهث مت تصميم وبناء مغير تردد يغذى محرك ثلاثي الأوجه، بالإضافة إلى درلمة وتحليل وتصميم محكم رقمي

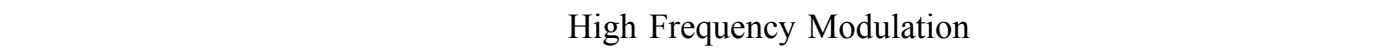
العملية للمحرك المغنى بالمحكم.

Keywords: Variable frequency inverter, digital controller, high frequency modulation and interfacing technique. 


\section{INTRODUCTION}

The induction motor drive systems can be classified into two types, namely, variable speed drive system or stator frequency control [1] and constant speed drive system $[2,3]$. The variable frequency converter can be implemented by using several techniques such as pulse width modulated sinusoidal voltage source inverter (PWM) [3], square wave voltage source inverter (six step modulations) [3]. The first technique is the (PWM), required an active filter and the second technique usually produced an increase in temperature of the machine. But these techniques has the following disadvantages complicated and more expensive $[4,5]$. So a simplified digital controller is speed from (600-3000) r.p.m and frequency range from (20-100) Hz, has be studied, analyzed, simulated and implemented as followed.

\section{DIGITAL CONTROLLER}

\subsection{Block diagram of the digital controller} system.

Figure (1) represents the block diagram of the designed controller. This controller starts from a predetermined frequency clock pulse generator, followed by special purpose counter which counts the generated clock pulse. The output of the special purpose counter is controlled logically to produce the three logic groups for the inverter. Through a frequency modulation interfacing that described in figure (4). The three modulated output pulses are given in figure (3). Finally the inverter is loaded by three phase induction motor.

\subsection{Description of the designed system:}

The system consists of:

- Stabilized-regulated power supply, with output voltage of 5V D.C and $500 \mathrm{~mA}$.

- Clock pulse generator, which generate squarewave stabilized output pulses with variable frequency $(200 \mathrm{~Hz}$ up to $1 \mathrm{kHz}$ ).

- Special purpose counter, which receives the output of clock pulse generator to be operate as a binary counter (ring counter) divided by 2, 4, 8 and 16 digit.

- Logical controller receives the output of ring counter to produce a three synchronize shift pulses. These pulses are shifted by $120^{\circ}$ with respect to the others.

- Frequency modulation adds an interfacing circuit to the output of the logic controller to produce a high frequency carrier signal.

- Interfacing circuit is the coupling circuit between both of digital controller circuit and the inverter power circuit. To isolation the controlling circuit from the power circuit.
- Power circuit is a simple three phase variable frequency inverter that receives its controlling signals from the interfacing output and feed the base of three phase inverter transistors. Three phase AC voltage signal to motor are the load of the designed inverter.

The detailed descriptions of these circuits are as follows:-

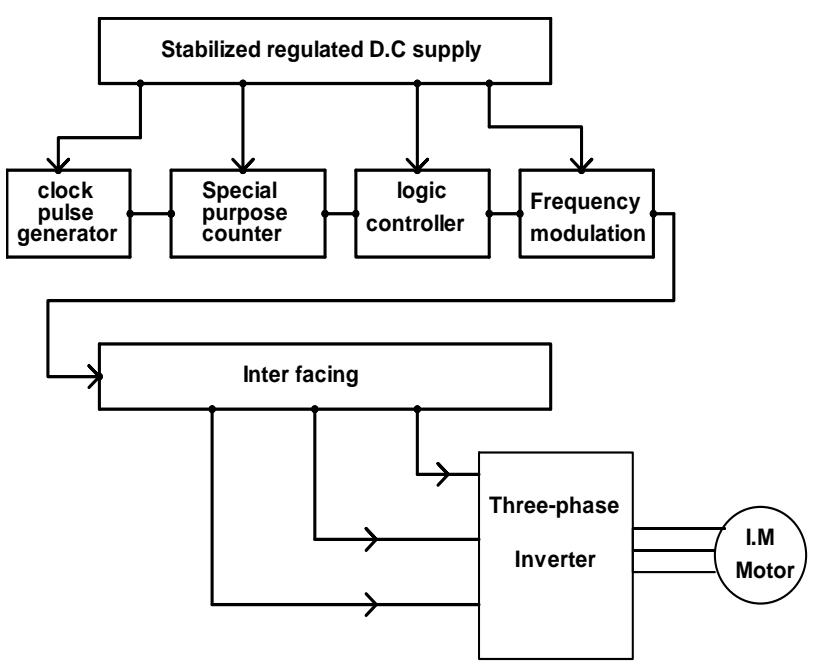

Fig. (1) Block diagram of the digital controller and power inverter.

\subsubsection{Logical controller.}

Figure (2) represent the logic diagram of the hardware implementation of the logical controller to generate the three separate shifted pulses with 120 。 phase shift from each other.

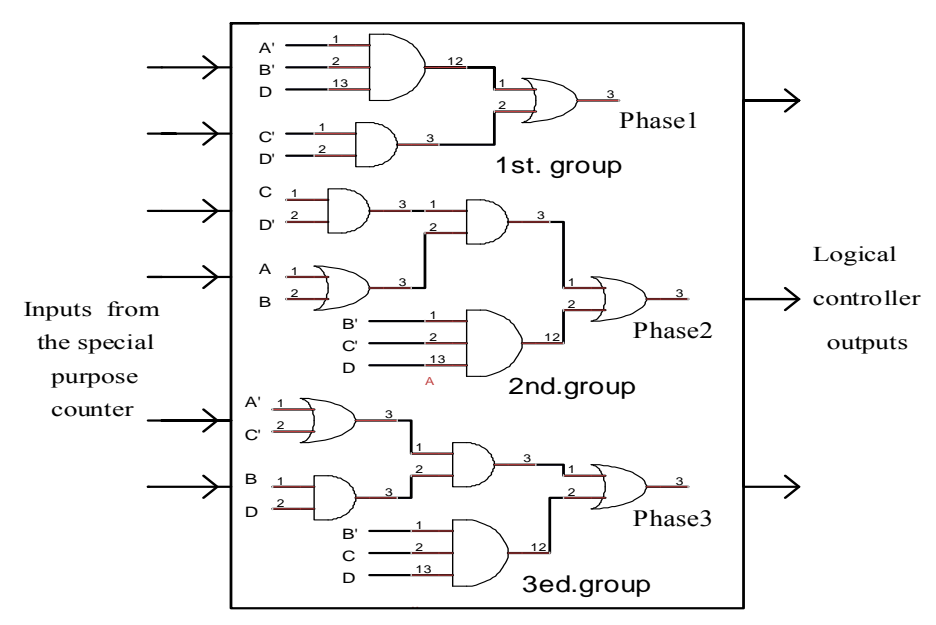

Fig. (2) Logical controller logic diagram.

The three separate pulses of the digital controller are given in figure (3). 
Phase A

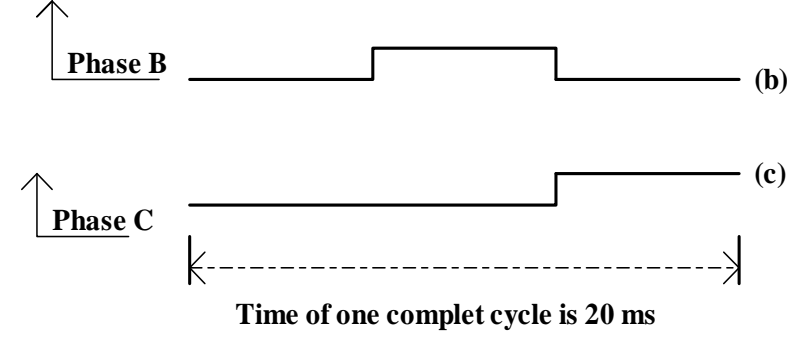

Fig. (3) Logic controller output pulses for three phases, (a), (b) and (c).

\subsubsection{Interface Circuit:}

The main goal of the interfacing circuit is to adjust the signal and to satisfy centered operating point of power transistor. The three main reasons required from the interfacing circuit are:-

1- Amplifier; the interfacing amplifies the signal to satisfy the transistor requirements with a predetermined values of suitable voltages.

2- Matching; the interfacing operates as an impedance matching circuit to satisfy the condition of maximum power transistor from one circuit to the other circuit.

3- Isolation; the interfacing circuit satisfying completes separation by using pulse transformer with air core to satisfy the protection to digital controller from the inverter circuit.

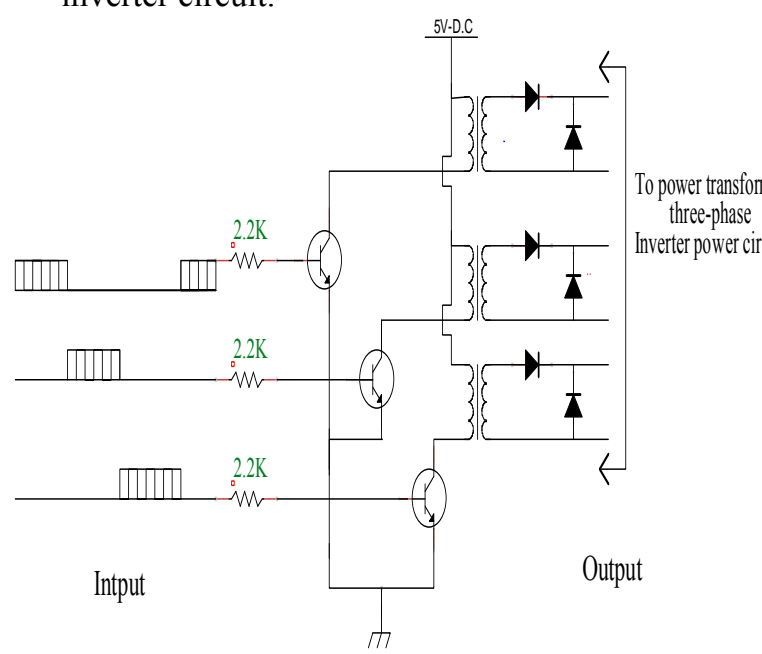

Fig. (4) Interfacing circuit

\subsubsection{INVERTER POWER CIRCUIT:}

The three phase inverter power circuit given in figure (5). Represents the 6-switchs which are supplied with 300 Volte D.C. This D.C. input voltage is converted by the power inverter circuit to a three phase A.C. voltage fed three phase induction motor. The three phase induction motor coils are shunted to three A.C. capacitors. That used as commutation capacitor beside a filter circuit to the inverter output.

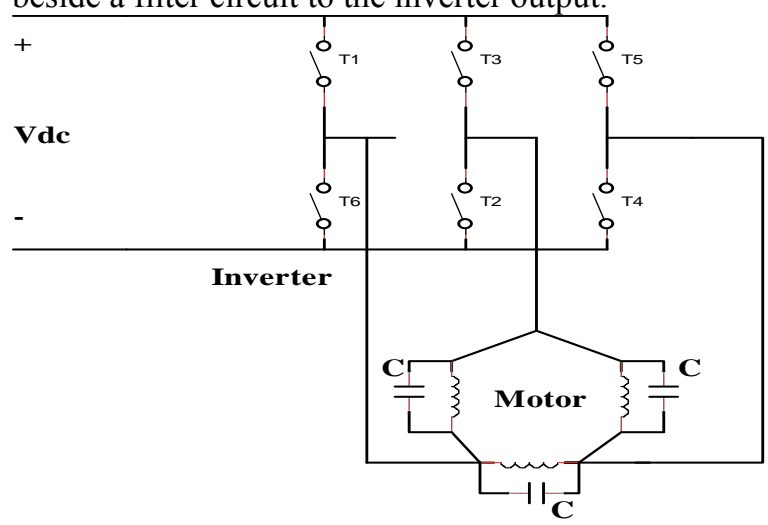

Fig. (5) Inverter power circuit diagram

\subsubsection{Inverter Operation circuit:}

The three phase inverter power circuit given in figure (5). Represents the 6-switches inverter which are supplied with 300 volt DC. this DC input voltage are converted by the power inverter circuit to a 3phase A.C. voltage. Feed the 3- phase induction motor. The three phase induction motor coils are shunted with 3-A.C. capacitor that used as a commutation capacitor beside a filter circuit to the inverter output.

\section{- Inverter operation}

The operation of the inverter circuit is divided into three regions on three modes mode $\mathbf{I}$ : both $\mathrm{T}_{1}$ and $\mathrm{T}_{2}$ are turned $\mathrm{ON}$ for $1 / 3$ the complete cycle.

mode II: mode two states at the end of mode I continuous ON tell the end of the second $1 / 3$ of the complete cycle in which T3, T4 are switched $\mathrm{ON}$.

mode III: it is the lasted $1 / 3$ end of the completed cycle in which $\mathrm{T} 5$ and $\mathrm{T} 6$ are switched ON.

\subsubsection{Hardware implementation of controller}

The complete circuit consists of [stabilized- regulated power supply, Clock pulse generator, Special purpose counter, Logical controller, frequency modulation, Interfacing circuit and inverter power circuit] which are given in figure (7). The output of clock pulse generator is the input to special purpose counter (SPC) (divided by 2, 4, 8 and16 bit). The output of SPC is the input to logical controller (3pulses shifted by $120^{\circ}$ ). The frequency modulation is modulates the (SPC) to suit operating transistor switches. The interfacing circuit is circuit coupling between logical controllers and the power inverter circuit, which is drive the motor. 


\subsubsection{Inverter circuit Analysis}

System equivalent circuit is illustrated in Figure (6) represents to the equivalent circuit of the inverter and induction motor during mode I of operation.

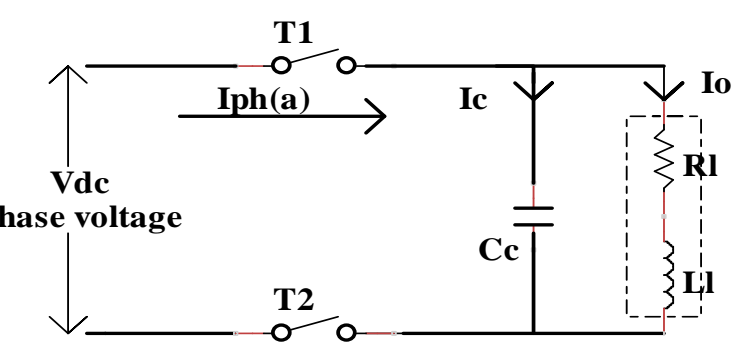

Fig. (6) Equivalent circuit of two phase of induction motor feeding with inverter (Mode-I).

Where;

$\mathrm{R}_{1}$ : total motor resistance

$\mathrm{L}_{1}$ : total motor reactance

Cc : commutation capacitor

$\mathrm{I}_{\mathrm{ph}}=\mathrm{i}_{\mathrm{t}}$ phase current

The corresponding differential equations describing this circuit;

$\frac{d v o}{d t}=\frac{1}{c} i_{t}-\frac{1}{c} i o$

$\frac{d i o}{d t}=\frac{v o}{L_{l}}-\frac{R_{l}}{L_{l}}$ io

The system differential equations can be written in a general state space form as;

$\frac{d}{d t}\left[\begin{array}{l}v_{o} \\ i_{o}\end{array}\right]=\left[\begin{array}{cc}0 & \frac{-1}{c} \\ \frac{1}{L_{l}} & \frac{-R_{l}}{L_{l}}\end{array}\right]\left[\begin{array}{l}v_{o} \\ i_{o}\end{array}\right]+\left[\begin{array}{c}\frac{1}{c} \\ 0\end{array}\right] E$

Then, the system state-space can be put in the form time domain as:

$v_{o}(t)=\frac{i_{t}}{C}\left(\alpha e^{-A T}+\beta e^{-B T}\right)+\frac{R^{*} i_{t}}{C}\left(J+H^{A T}+K e^{-B T}\right),(V)$
$i_{o}(t)=\frac{R_{l}^{*} i_{t}}{C^{*} L_{l}}\left(\begin{array}{lll}J+H & e^{-A T}+K & \left.e^{B T}\right),\end{array}\right.$
Where,

$$
\begin{aligned}
& A=\frac{-R l}{2 L l}+\sqrt{\frac{R l^{2}}{4 L l^{2}}-\frac{1}{C L l}}, \quad B=\frac{-R l}{2 L l}-\sqrt{\frac{R l^{2}}{4 L l^{2}}-\frac{1}{C L l}} \\
& J=\frac{1}{A^{*} B}, \quad H=\frac{-1}{A(-A+B)}, \quad K=\frac{-1}{B(-B+A)} \\
& \alpha=\frac{1}{(-A+B)}, \quad \beta=\frac{1}{(-B+A)},
\end{aligned}
$$




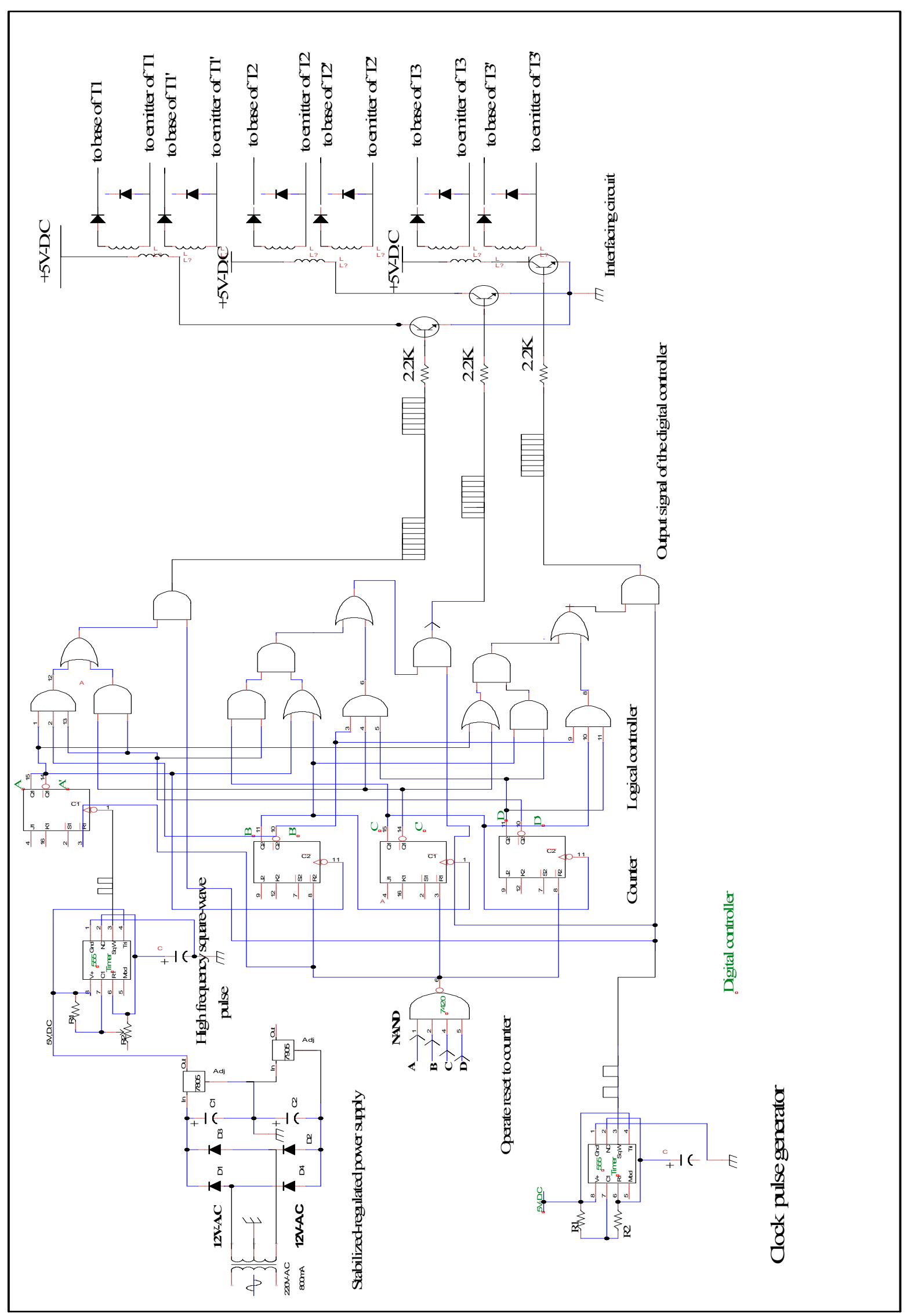

Fig. (7) The complete circuit diagram 


\subsubsection{PRACTICAL MEASURED RESULTS.} Controlling signal of digital controller is supplied the inverter. Square wave pulses shifted by $120^{\circ}$ is illustrated in figure (8).

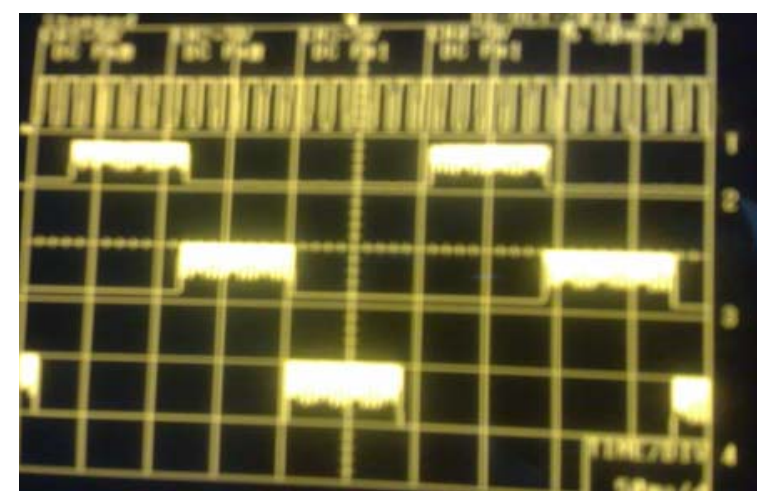

Fig. (8) Logical controller output with frequency modulation.

Voltage.5volt/divi.-time. $5 \mathrm{~m} . \mathrm{sec} / \mathrm{div}$

1- Clock pulse output, 2-phase (1)

3- Phase (2), 4-Phase (3).

\section{SIMULATION RESULTS.}

Figure (9) shows the analytical simulation result for torque speed characteristics. These characteristics are given at different frequencies. Maximum and full load torques are presented.

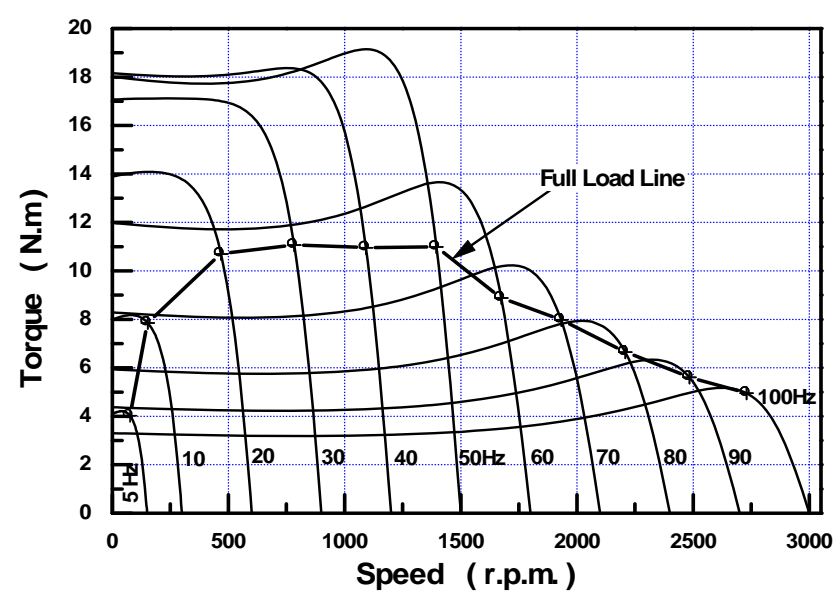

Fig. (9) Motor torque versus speed at different frequencies

\section{CONCLUSION.}

This paper presents a simplest open loop digital controller that control a three-phase induction motor of (.75HP) has been suggested, studied, designed, implemented, and tested. Practical results such as controlling pulse that counter frequency range from $20 \mathrm{~Hz}$ up to $100 \mathrm{~Hz}$ is obtained. The simulation results relies control in the speed of induction motor by controlling the frequency.

\section{REFRENCES.}

[1] S. M. Wankhede, R.M.Holmukhe, Miss.A.M.Kadam, Miss.P.Rashinde, P.S.Chaudhari. "Microcontroller Based Control of Three-phase Induction Motor Using PWM Technique" IEEE International Conference on Electrical Energy and Networks (ICEEN) PP. 2630, 2011.

[2] X. D. Xue and K. W. E. Cheng. "An Energy-saving Scheme of Variable Voltage Control for Three-Phase Induction Motor Drive Systems " the2nd inter. Conf. on power electronics system and application, PP.241-288, 2006.

[3] Dong-Choon, Young-Sin Kim "Control of Single-Phase AC/DC/AC PWM Converters for Induction Motor Drives" IEEE Ministry of Commerce, Industry and Energy (MOCIE) PP. 16, 2005.

[4] Soheir M. A. Allahony, Ahmed A. Aboumobarka, Magdy A. Koutb, H. Mousa1" Hardware Implementation of Digital Signal Controller for Three Phase Vector Controlled Induction Motor" JATIT. All rights reserved. PP. 15,2009

[5] H. N.Hickok "Adjustable speed a tool for saving energy losses in pumps, fan, and compressors" IEEE Trans. On IA, vol.21, no. 1, PP.124-136, 1985.

[6] Brian A. Welchko and Thomas A. Lipo "A Novel Variable-Frequency Three-Phase Induction Motor Drive System Using Only Three Controlled Switches" IEEE Trans. vol.37, PP. 1739-1745, 2001. 